Gut, 1980, 21, 835-839

\title{
Small erythematous mucosal plaques: an endoscopic sign of Crohn's disease
}

\author{
A WATIER, G DEVROEDE,* B PEREY, H HADDAD, \\ P MADARNAS, AND P GRAND-MAISON
}

From the Departements de Chirurgie Generale, Pathologie, Medecine (Section de Gastroenterologie) et Medecine de Famille, Faculté de Medecine, Université de Sherbrooke, Sherbrooke, Quebec, Canada

SUMMARY A non-ulcerated granulomatous lesion of the large bowel mucosa has been found in 11 patients, nine of whom already had or eventually developed classical features of Crohn's disease. These lesions, which are multiple, consist of small well-circumscribed raised erythematous plaques surrounded by normal mucosa. At biopsy there is focal haemorrage of the lamina propria, rupture of the crypts, release of mucus, and frank granulomatous reaction with giant cell formation. The lesion may be reversible or be followed by the classical mucosal ulcerations. They may occur in the presence or the absence of classical lesions of Crohn's disease elsewhere in the gastrointestinal tract. As this non-ulcerated lesion may occur in isolation, it may provide the initial clue to the diagnosis of Crohn's disease.

Since its initial description in $1932,{ }^{1}$ Crohn's disease has presented a number of diagnostic dilemmas. The diagnosis may be difficult to establish at any stage of the disease but particularly in early acute disease of the large bowel. It is generally accepted that aphthoid ulcers are the earliest endoscopic lesions seen in Crohn's colitis. ${ }^{23}$ This implies that the colonic mucosa is ulcerated early in the course of the disease. Nevertheless, one may speculate that hitherto unidentified non-ulcerated mucosal lesions may occur in this disease and may even precede ulceration. Non-ulcerated granulomatous lesions were indeed observed in 11 patients, nine of whom have a proven diagnosis of Crohn's disease.

\section{Methods}

From 1 May 1970 to 1 May 1979, 210 patients were diagnosed at the Centre Hospitalier Universitaire de Sherbrooke, as suffering from Crohn's disease, on the basis of accepted clinical, radiological endoscopic, and histological criteria. ${ }^{4-9}$ Nine of these patients were found at their first proctosigmoidoscopy to have multiple well-circumscribed

*Address for reprint requests: Dr G Devroede, Département de Chirurgie, Centre Hospitalier Universitaire, Sherbrooke Québec, Canada, J1H 5 N4.

Received for publication 20 March 1980 raised, non-ulcerated, erythematous plaqnes measuring 2 to $5 \mathrm{~mm}$ and surrounded by an intact mucosa with a normal vascular pattern. Two additional patients presented identical lesions but have not yet developed other diagnostic signs of Crohn's disease.

Each of the 11 patients underwent repeated endoscopies (two to seven) and biopsies (one to 10), had a barium enema, barium meal, and radiographs of the small bowel during the initial work-up. Stools were studied for pathogenic bacteria and parasites including Yersinia enterolytica. Other granulomatous diseases were excluded with special histological stains (Grocott, Ziehl, immunofluorescence, auramine-rhodamine), serology (VDRL) and skin test (PPD).

Patients were prepared for proctosigmoidoscopy with a Fleet enema (Registered Trade Mark Charles E. Frosst Co.) and none displayed mucosal changes resulting from the preparation as defined by previously reported criteria. ${ }^{10}$ The erythematous lesions were examined with a magnifying lens $(\times 2.5)$ to confirm the absence of ulceration. The glistening appearance of the mucosa had an unbroken appearance, in contrast with aphthoid ulcers where a tiny crater, sometimes haemorrhagic, is seen in the midst of the lesion. Single or multiple biopsies were taken by the grasp technique directly in the centre of the lesion. Specimens were fixed in buffered $10 \%$ formalin and sections were stained with haema- 


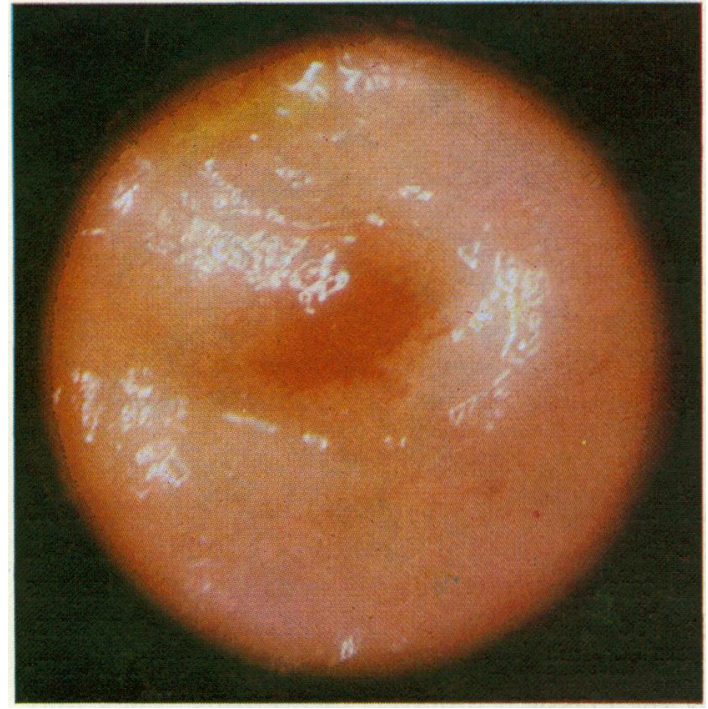

Fig. 1 Small erythematous mucosal plaques. toxylin and eosin. Twenty serial sections were made to further establish the absence of ulceration.

\section{Results}

Eleven patients were found to have on their first proctosigmoidoscopic examination multiple small well-circumscribed raised erythematous plaques surrounded by normal mucosa (Fig. 1).

There were six women and five men. Their age varied from 20 to 49 years (nine were under 30 years of age). The presenting clinical picture (Table 1) was characterised mainly by diarrhoea ( $82 \%)$, minimal rectal bleeding $(82 \%)$, abdominal pain (64\%), weight loss $(27 \%)$, fever, and aphthous stomatitis $(18 \%)$. Two patients had been operated on for anorectal fistulae and ischiorectal abcesses (nos. 4, and 7); one of them (no. 4) also developed bilateral sacroiliitis and was HLA-B27 positive. Two patients (nos. 2, and 6) developed Crohn's disease of the vulva, ${ }^{11}$ one of them (no. 6) also had

Table 1 Presenting clinical picture

\begin{tabular}{|c|c|c|c|c|c|c|c|c|c|}
\hline & \multicolumn{2}{|c|}{$\begin{array}{l}\text { Sex, age } \\
(y r)\end{array}$} & \multirow{2}{*}{$\begin{array}{l}\text { Diarrhoea } \\
-\end{array}$} & \multirow{2}{*}{$\begin{array}{l}\begin{array}{l}\text { Rectal } \\
\text { bleeding }\end{array} \\
+\end{array}$} & \multirow{2}{*}{$\begin{array}{l}\text { Abdominal } \\
\text { pain }\end{array}$} & \multirow{2}{*}{$\begin{array}{l}\text { Weight } \\
\text { loss }\end{array}$} & \multirow{2}{*}{$\begin{array}{l}\text { Fever } \\
-\end{array}$} & \multirow{2}{*}{$\begin{array}{l}\text { Stomatitis } \\
-\end{array}$} & \multirow{2}{*}{$\begin{array}{l}\text { Duration of symptoms before } \\
\text { investigation (months) } \\
15 \mathrm{~d}\end{array}$} \\
\hline 1 & $\mathbf{F}$ & 22 & & & & & & & \\
\hline 3 & $\mathbf{M}$ & 20 & - & + & + & + & + & - & 3 \\
\hline 4 & $\mathbf{M}$ & 20 & + & + & - & - & - & + & 36 \\
\hline 5 & $\mathbf{M}$ & 36 & + & + & + & - & - & - & 6 \\
\hline 6 & $\mathbf{F}$ & 20 & + & + & - & + & - & - & 12 \\
\hline 8 & $\mathbf{F}$ & 20 & + & - & + & + & + & + & 12 \\
\hline 9 & $\mathbf{M}$ & 30 & + & + & + & - & - & - & $3 w$ \\
\hline 10 & $\mathbf{F}$ & 20 & + & + & + & - & - & - & 1 \\
\hline 11 & $\mathbf{M}$ & 30 & + & + & - & - & - & - & 2 \\
\hline
\end{tabular}

Table 2 Endoscopy and radiology

\begin{tabular}{|c|c|c|c|c|}
\hline \multirow{2}{*}{\multicolumn{2}{|c|}{$\begin{array}{l}\text { Proctosigmoidoscopies (no.) and duration } \\
\text { of endoscopic follow-up (months) }\end{array}$}} & \multirow{2}{*}{$\begin{array}{l}\text { Proctosigmoidoscopic findings } \\
\text { (in chronological sequence) }\end{array}$} & \multicolumn{2}{|c|}{ Initial $x$-ray findings } \\
\hline & & & $\begin{array}{l}\text { Barium enema } \\
+\end{array}$ & Small bowel $x$-rays \\
\hline $\begin{array}{r}1 \\
2 \\
3 \\
4 \\
5 \\
6 \\
7 \\
8 \\
9 \\
10 \\
11\end{array}$ & $\begin{array}{l}7 \text { in } 8 \\
2 \text { in } 5 \\
7 \text { in } 12 \\
3 \text { in } 6 \\
5 \text { in } 10 \\
5 \text { in } 8 \mathrm{yr} \\
3 \text { in } 9 \mathrm{yr} \\
2 \text { in } 2 \\
3 \text { in } 3 \\
3 \text { in } 16 \\
8 \text { in } 16 \mathrm{yr}\end{array}$ & $\begin{array}{l}++(+0)++(+0)+ \\
+0 \\
+(+*)(+*)(+0)(+0)(+0)(+0) \\
+0+ \\
++++* \text { FIST } \\
+-+-(+*) \\
+-(+*) \\
++ \\
++- \\
+-- \\
++---- \text { PROCT }\end{array}$ & $\begin{array}{l}+ \\
+ \\
+ \\
- \\
+ \\
+ \\
+ \\
-\end{array}$ & $\begin{array}{l}- \\
+ \\
+ \\
+ \\
- \\
+ \\
+ \\
+\end{array}$ \\
\hline & $\begin{array}{l}\text {-circumscribed raised no } \\
\text { ns. } \\
\text { udinal well-circumscribe }\end{array}$ & $\begin{array}{l}\text { erated erythematous plaques. } \\
\text { erations. }\end{array}$ & $\begin{array}{l}\text { Jultaneous lesion } \\
\text { Fistula in ano. } \\
\text { Proctitis. } \\
\text { mments in Resu }\end{array}$ & ion. \\
\hline
\end{tabular}


Table 3 Biopsy and histology

\begin{tabular}{rll}
\hline & $\begin{array}{l}\text { Biopsies taken } \\
\text { (no.) }\end{array}$ & $\begin{array}{l}\text { Positive biopsies (granuloma) } \\
\text { (no.) }\end{array}$ \\
\hline 1 & 10 & 6 \\
2 & 4 & $3^{*}$ \\
3 & 2 & 2 \\
4 & 3 & 2 \\
5 & 5 & 3 \\
6 & 5 & $4^{*}$ \\
7 & 2 & $2 \dagger$ \\
8 & 3 & 2 \\
9 & 4 & 3 \\
10 & 1 & 1 \\
11 & 3 & 3 \\
\hline
\end{tabular}

*Crohn's disease of the vulva also proven by biopsy.

$\dagger$ Histological diagnosis of Crohn's disease also made on resected small and large bowel.

erythema nodosum. The duration of symptoms before investigation ranged from 15 days to three years. The duration of the clinical history was six months or less in seven patients.

The endoscopic follow-up ranged from five months to nine years. Gastrointestinal radiographs were always done during the first month of investigation. Patients nos. 6, 7, and 11 had multiple radiographs of the small and large bowel.

In seven patients (Table 2) these erythematous plaques preceded the appearance of aphthoid or ulcerated lesions in the rectum. This change took place in less than one year in five of these patients. In the four remaining patients the erythematous plaques either persisted in the absence of other endoscopic lesions (no. 8) or disappeared, leaving a normal rectum in two cases (nos. 9 and 10) and non-specific proctitis in the last case (no. 11). Radiographic findings were typical of Crohn's disease in two out of these four patients.

Eight patients initially had or later developed typical radiological signs of Crohn's disease in the small and or large bowel. One patient (no. 5) with normal radiographic findings, refused control radiography but later developed a fistula in ano and aphthoid lesions. Patient no. 7 underwent laparotomy for biliary surgery, one year after the positive endoscopic findings, and was found to have creeping fat and multiple granulomatous lymph nodes in spite of repeated normal radiographs of the bowel. She underwent ileal resection six years later and the pathological diagnosis was that of Crohn's disease.

Biopsies were taken at each endoscopy (Table 3). Histological evaluation of the biopsies of the erythematous plaques always showed an abnormal mucosa which contained granulomas. There was mucosal oedema and focal haemorrhage in the superficial zone of the lamina propria (Fig. 2). Varying degrees of polymorphonuclear infiltration were present. Distortion of the crypts was also noted. There was focal infiltration of the crypts by neutrophils and eosinophils extending through the basal membrane (Fig. 3a). Obliteration of the crypt by a concentric atrophy (Fig. 3b) or massive and abrupt rupture of the crypt wall with formation of crypt abscesses (Fig. 3c) were also noted. Liberation of mucus (Fig. 3d) about the area of destruction was accompanied by a frank granulomatous reaction with giant cell formation (Fig. 3e).

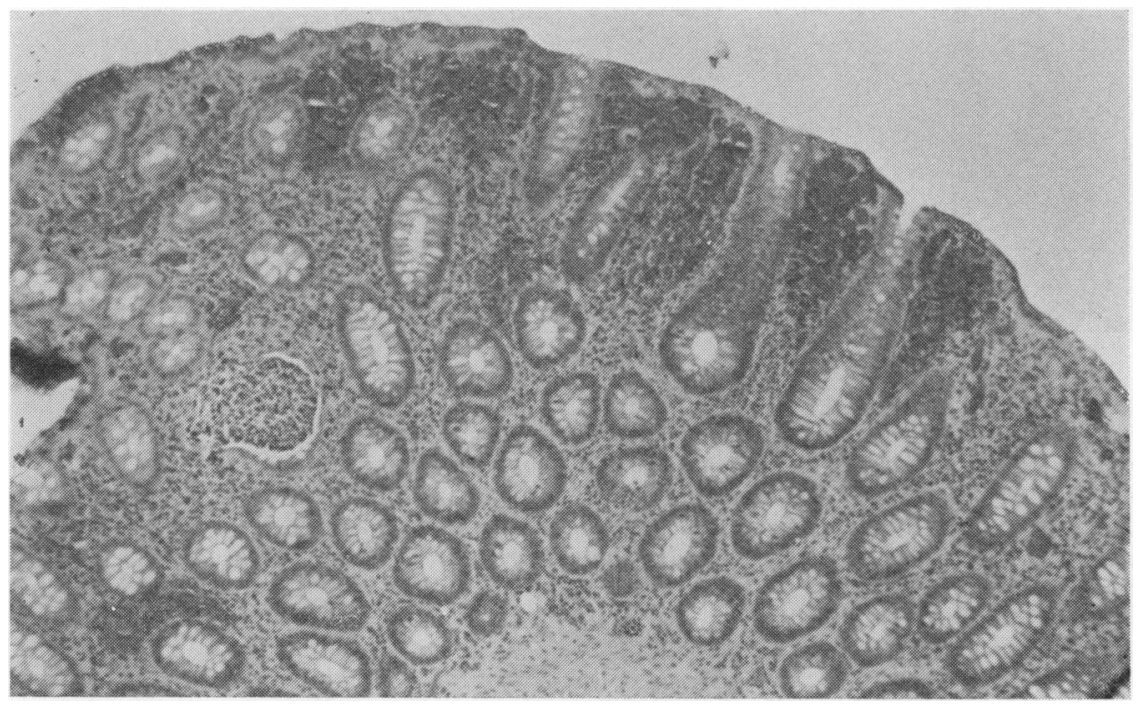

Fig 2 Zone of haemorrhage infiltrating the upper lamina propria. Crypt abscess also visible. $H$ and $E, \times 160$ 

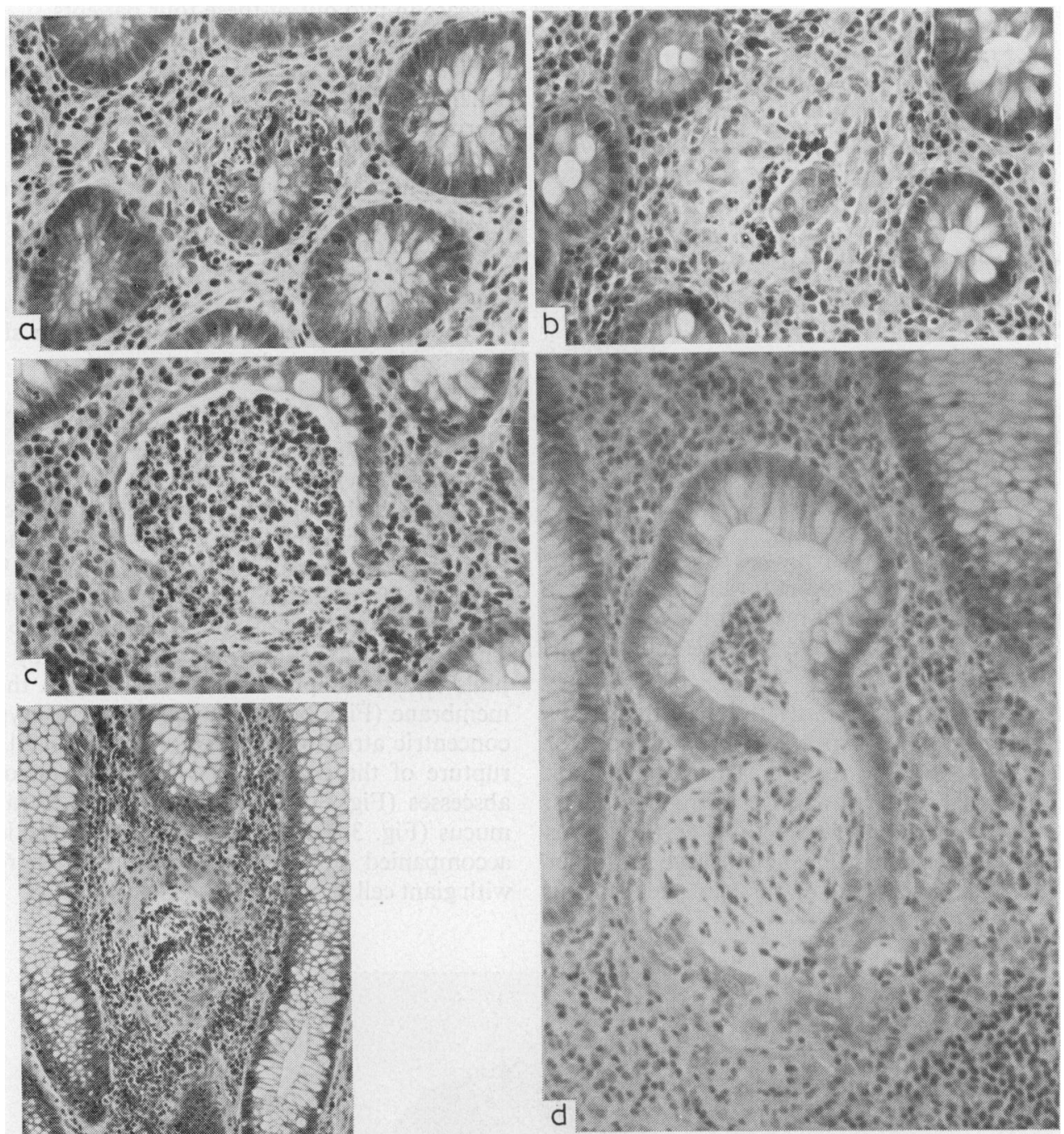

Fig. 3 (a) Infiltration of crypt by polymorphonuclears across the basal membrane. $H$ and $E, \times 400$.

(b) Concentric atrophy of crypt with residual epithelial cells surrounded by granulomatous inflammation. $H$ and $E, \times 400$. (c) Abrupt inflammatory invasion of crypt wall with formation of microabscess. $H$ and $E, \times 400$. (d) Rupture of crypt wall and liberation of mucus and early granulomatous reaction. $H$ and $E, \times 250$. (e) Advanced granulomatous reaction surrounding a destroyed segment of crypt. $H$ and $E, \times 63$. 


\section{Discussion}

The typical endoscopic appearance of Crohn's disease is that of mucosal ulcers which are single or multiple, linear, longitudinal, well-circumscribed, and may vary in length, width, and depth. ${ }^{7}$ Aphthoid ulcers are considered to be the earliest mucosal lesion that may be recognised endoscopically. However, the histological features of Crohn's disease have been observed in the rectal mucosa in spite of a normal endoscopic appearance. ${ }^{1213}$ To our knowledge, no grossly visible non-erosive lesion of the bowel mucosa has yet been described in this disease.

The present report provides strong evidence that the erythematous plaques that are described are lesions of Crohn's disease. Indeed, nine of our 11 patients either already had or have since developed classical clinical endoscopic, radiological, and histological features of the disease. Furthermore, these lesions all contained granulomas. Finally, we did not see such erythematous plaques in the 15840 proctosigmoidoscopies that we also carried out during the same period.

Such lesions may disappear as other Crohn's lesions do. They are also probably part of the endoscopic continuum of Crohn's disease. In fact, they tend to make their first appearance early in the course of the disease, as they preceded the appearance of aphthoid and/or typical longitudinal ulcerations in at least seven of our 11 patients. One may speculate that some of the erythematous plaques become ulcers. On the one hand, it is more difficult to speculate that each ulcer is preceded by a plaque. Indeed, only nine (cases 1 to 9) of our 210 proven cases of Crohn's disease diagnosed in the same period displayed these lesions; this is an incidence of less than 5\%. All other cases of Crohn's disease also underwent repeated proctosigmoidoscopies but the plaques were not found. On the other hand, in patients where such lesions did occur the plaques tended to be a persistent feature (eight out of nine cases) found one or more times during the subsequent endoscopic follow-up. These observations suggest that the erythematous plaques are distinguishing features of a very small minority of patients with Crohn's disease.

When these small plaques occur in isolation they may easily be overlooked and should always be biopsied. They may provide the earliest known clue to the diagnosis of Crohn's disease and should lead to a careful endoscopic and clinical follow-up.

\section{References}

'Crohn BB, Ginzburg L, Oppenheimer GD. Regional ileitis: A pathologic and clinical entity. JAMA 1932; 99: 1323-9.

${ }^{2}$ Morson BC. In: Engl A, Larsson T, eds. Regional enteritis. (Crohn's disease). Histopathology. Skandia International 5th Symposia, Nordiska, Stockholm: Bokhandelns Förlag, 1971: 15-33.

${ }^{3}$ Whitehead R. Pathology of Crohn's disease of the colon. In: Kirsner JB, Shorter RG, eds. Inflammatory bowel disease. Philadelphia: Lea \& Febiger, 1975: 182-98.

${ }^{4}$ Whitehead R. Mucosal biopsy of the gastrointestinal tract. In: Major problems in pathology, 3. London: Saunders, 1973: 139-66.

5ohnson WD, Roth JLA. Diagnosis and differential diagnosis of chronic ulcerative colitis and Crohn's colitis. In: Kirsner JB, Shorter RG, eds. Inflammatory bowel disease. Philadelphia: Lea \& Febiger, 1975: 201-24.

${ }^{6}$ Marshak RH, Lindner AE. Radiologic diagnosis of chronic ulcerative colitis and Crohn's disease of the colon. In: Kirsner JB, Shorter, RG, eds. Inflammatory bowel disease. Philadelphia: Lea \& Febiger, 1975: 241-76.

${ }^{7}$ Spencer RJ. Endoscopy in chronic ulcerative colitis and Crohn's colitis. In: Kirsner JB, Shorter RG, eds. Inflammatory bowel disease. Philadelphia: Lea \& Febiger, 1975: 225-40.

${ }^{8}$ Wall AJ, Kirsner JB. Ulcerative colitis and Crohn's disease of the colon: Symptoms, signs, and laboratory aspects. In: Kirsner JB, Shorter RG, eds. Inflammatory bowel disease. Philadelphia: Lea \& Febiger, 1975: 101-8. ${ }^{9}$ Brooke BN, Cave DR, Gurry JF, King DW. Crohn's disease: aetiology, clinical manifestations and management. London: Macmillan, 1977: 1-113.

${ }^{10}$ Leriche M, Devroede G, Sanchez G, Rossano J. Changes in the rectal mucosa induced by hypertonic enemas. Dis Colon and Rectum 1978; 21: 227-236.

${ }^{11}$ Devroede G, Schlaeder G, Sanchez G, Haddad H. Crohn's disease of the vulva. Am J Clin Path 1975; 63: $348-58$.

${ }^{12}$ Korelitz BI, Sommers SC. Involvement of the normal appearing rectum in Crohn's disease determined by rectal biopsy and cell counts of rectal mucosa. (Abstract) Gastroenterology 1976; 70: 904.

${ }^{13}$ Rickert RR, Carter HW. The gross, light microscopy and scanning electron microscopic appearance of early lesion of Crohn's disease. Scanning Electron Microsc 1977; 2: 179-86. 